\title{
Article
}

\section{Drought and Anthropogenic Effects on Acacia Populations: A Case Study from the Hyper-Arid Southern Israel}

\author{
Rachel Armoza-Zvuloni ${ }^{1, *}$, Yanai Shlomi ${ }^{1}$, Rachamim Shem-Tov ${ }^{1}$, Ilan Stavi ${ }^{1,2}$ (D) and Itay Abadi ${ }^{1,3}$ \\ 1 Dead Sea and Arava Science Center, Yotvata 88820, Israel; yanai.samar@gmail.com (Y.S.); \\ rastov@gmail.com (R.S.-T.); istavi@adssc.org (I.S.); itay@adssc.org (I.A.) \\ 2 Eilat Campus, Ben-Gurion University of the Negev, Eilat 88100, Israel \\ 3 Institute of Archaeology, and The Jack, Joseph and Morton Mandel School for Advanced Studies in the \\ Humanities, The Hebrew University of Jerusalem, Mount Scopus, Jerusalem 9190501, Israel \\ * Correspondence: rachel@adssc.org; Tel.: +972-52-8215249
}

Citation: Armoza-Zvuloni, R.; Shlomi, Y.; Shem-Tov, R.; Stavi, I.; Abadi, I. Drought and Anthropogenic Effects on Acacia Populations: A Case Study from the Hyper-Arid Southern Israel. Soil Syst. 2021, 5, 23. https:// doi.org/10.3390/soilsystems5020023

Academic Editors: Juan Albaladejo and Heike Knicker

Received: 29 December 2020

Accepted: 16 March 2021

Published: 1 April 2021

Publisher's Note: MDPI stays neutral with regard to jurisdictional claims in published maps and institutional affiliations.

Copyright: (c) 2021 by the authors. Licensee MDPI, Basel, Switzerland. This article is an open access article distributed under the terms and conditions of the Creative Commons Attribution (CC BY) license (https:// creativecommons.org/licenses/by/ $4.0 /)$.

\begin{abstract}
Acacia encompasses a keystone genus across the Middle Eastern and African drylands. This study assesses the dynamics of Acacia populations in two ephemeral stream channels (Nahal Naomi and Nahal Yael) in the hyper-arid Arava region following the establishment of a dam in the upstream channel of Nahal Yael and a long-term regional drought episode. The assessments were conducted at the individual and population levels, for a period of 45 years (during 1972, 1994 and 2017). In Nahal Naomi, the population increased by 35\% during 1972-1994 (a relatively rainy period) and experienced low mortality (net change of $+1.6 \%$ year $^{-1}$ ). However, following a regional drought episode between 1995 and 2009, this population decreased by $57 \%$ (net change of $-2.5 \%$ year ${ }^{-1}$ ). In Nahal Yael, the acacia population declined by $66 \%$ during $1972-1994$ (net change of $-1.6 \%$ year $^{-1}$ ). Between 1994-2017, this population was co-affected by dam and drought, with no recruitment, and declined by $70 \%$ (net change of $-2.0 \%$ year $^{-1}$ ). By examining the tree's specific location, species, age and state of preservation of dead individuals, we identified factors that influence tree mortality, and highlighted the adverse impacts of natural and anthropogenic disturbances on Acacia populations in hyper-arid environments.
\end{abstract}

Keywords: alluvial fan; annual rainfall; Arava Valley; long-term population dynamics; hyper-arid regions; acacia populations

\section{Introduction}

Acacia is the dominant tree genus throughout the drylands of the Middle Eastern and Africa. Acacias have significant ecological and spiritual roles in these dryland ecosystems: it is a major food source for herbivores (wild and domestic), provides nesting habitats, shade, fills a central role in nutrient cycling, used as fuelwood and encompasses important cultural roles in traditional desert societies [1-10]. Therefore, Acacia is defined as a 'keystone genus' both ecologically and culturally $[7,9]$.

Acacia populations are facing significant challenges that may affect their demographic patterns. Climatic change in drylands can intensify desertification and increase frequency and magnitude of drought periods [11]. In addition to natural changes, misuse of the acacia by local communities may threaten its populations [3]. Studies assessing acacia populations in southern Israel showed that interferences related to changes in the natural hydrological system put the acacia populations at risk [12-14]. Geographic characteristics, such as latitude [15], mesotopography [15-17], and lithology [18] also affect distribution of Acacia populations.

In order to assess the effects of natural changes and anthropogenic disturbances on the acacias, the long-term dynamics in their population must be investigated. In several studies, acacias' mortality rates (i.e., \% mortalities of the entire population) over time were assessed using aerial photos and field surveys $[3,13,14,16,19]$. 
Various factors make it difficult to assess the dynamics of acacia populations. Acacia are slow growing and long living trees, with low recruitment rates [20-24]. Also, dead individuals often remain standing for decades $[12,13,25]$. In some cases, individuals that appear to be dead are in fact alive, and regenerate following the next rainy episode. In many Middle Eastern and African regions, acacias are used as a food source for livestock, charcoal production, or other uses [2,3,26,27]. In such cases, dead trees do not remain on-site, and demographic changes cannot be fully determined.

A prolonged drought period that occurred across the Arava Valley (in southern Israel) between 1995 and 2009 significantly reduced the frequency and magnitude of flashfloods [28,29]. Decreased annual rainfall and increased anthropogenic disturbances have raised concerns regarding the state of acacia populations across the region [12,13,15,16,25,30-32]. Despite previous studies, the combined effect of natural and anthropogenic stressors on mortality and recruitment rates of acacia in hyper arid regions is not yet well understood.

The main objective of the present study was to assess the effect of long-term drought and anthropogenic disturbances on mortality and recruitment rates of acacias in the hyperarid southern Arava region. We assessed changes that took place at the individual and population levels by using data that was obtained in three surveys conducted in 1972, 1994 and 2017. We assessed the trees' location, species, age, and the state of preservation of dead trees. We hypothesized that compared to only natural stresses, the combination of natural and anthropogenic stresses increases mortality rates of acacias.

\section{Materials and Methods}

\subsection{Regional Settings}

Nahal Yael and Nahal Naomi are two adjacent wadis (ephemeral streambeds), tributaries of Nahal Roded, located ca. $4 \mathrm{~km}$ north of the Gulf of Aqaba (Figure 1). The catchment areas of these two alluvial fans are quite small and are comparable in size (Yael

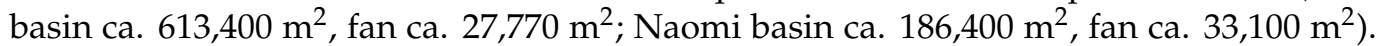
The relief and lithological characteristics of the two catchment basins are similar, composed mainly of magmatic and metamorphic rocks with a high percentage of exposed rocky surfaces on the hillslopes (see Enzel et al. [33] for detailed description). As part of a long-term hydrological research project initiated in 1977, a dam was established in Nahal Yael, in the transition zone between the upstream catchment section and the fan [34]. Since then, the dam has prevented runoff from reaching the alluvial fan, adversely affecting the downstream vegetation [14]. Photographs taken from the dammed wadi in 1994 and 2017 demonstrate the structure and the size of the alluvial fan, as well as the condition of the nearby Acacia trees (Figure 2). The nearby catchment basin of Nahal Naomi, which has not been modified by anthropogenic activities, was selected as a reference site. The perennial vegetation across the region is restricted to the stream channels. The two dominant tree species in the area are Acacia raddiana Savi (recently renamed Vachellia tortilis subsp. raddiana (Savi) Kyal. \& Boatwr) and Acacia tortilis (recently renamed Vachellia tortilis; subsp. tortilis (Forssk.) Galasso \& Banfi) [35]. The largest native herbivores are ibex (Capra nubiana) and gazelle (Gazella dorcas), which both feed on acacia leaves and pods. No livestock graze throughout the region. Acacias are protected by law and any anthropogenic use is illegal, even after their death. The region's climate is characterized by high temperatures (mean daily temperatures of $32{ }^{\circ} \mathrm{C}$ in July and $16{ }^{\circ} \mathrm{C}$ in December), low relative humidity ( $24 \%$ in July and $47 \%$ in December), and high potential evapotranspiration (13.6 and $4.2 \mathrm{~mm} \mathrm{day}^{-1}$ in July and December, respectively; summarized by Stavi et al. [15]). Mean annual rainfall across the region is characterized by high temporal and spatial variability [36,37], averaging $26.6 \mathrm{~mm}_{\text {year }}{ }^{-1}$ between 1949 and 2020 (ranging between 2-97 $\mathrm{mm}_{\text {year }}{ }^{-1}$ ). Between 1995 and 2009, a severe drought episode across the southern Arava Valley substantially decreased annual rainfall, flood frequency and magnitude [25,28,29]. Katz et al. [29], who monitored floods entering the Gulf of Aqaba from the Kinnet Canal (that drains Nahal Roded), reported only one flood event between 1995 and 2009, which occurred in 1997. The 
next flood event in the region occurred in 2010. This flood event stopped the sequence of drought years.
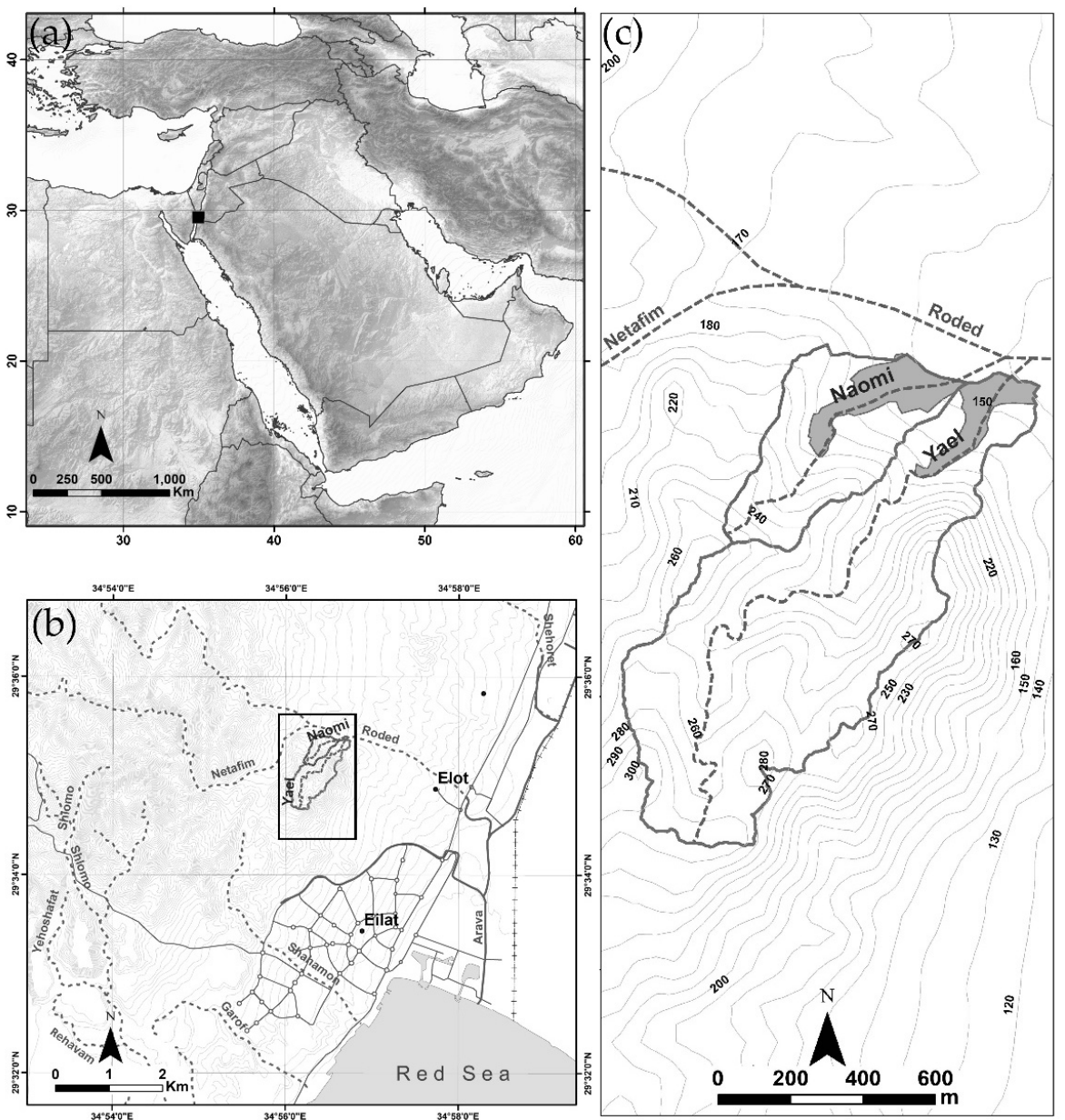

Figure 1. The study area; (a) The study site (marked by black square) is in the southern Negev of Israel, between the Arabian Peninsula and the deserts of northeastern Africa; (b) Nahal Naomi and Nahal Yael (boxed area) are tributaries of Nahal Roded north of the city of Eilat and the Gulf of Aqaba; (c) The catchment areas of these two tributaries are small, and their alluvial fans are comparable in size (gray area).

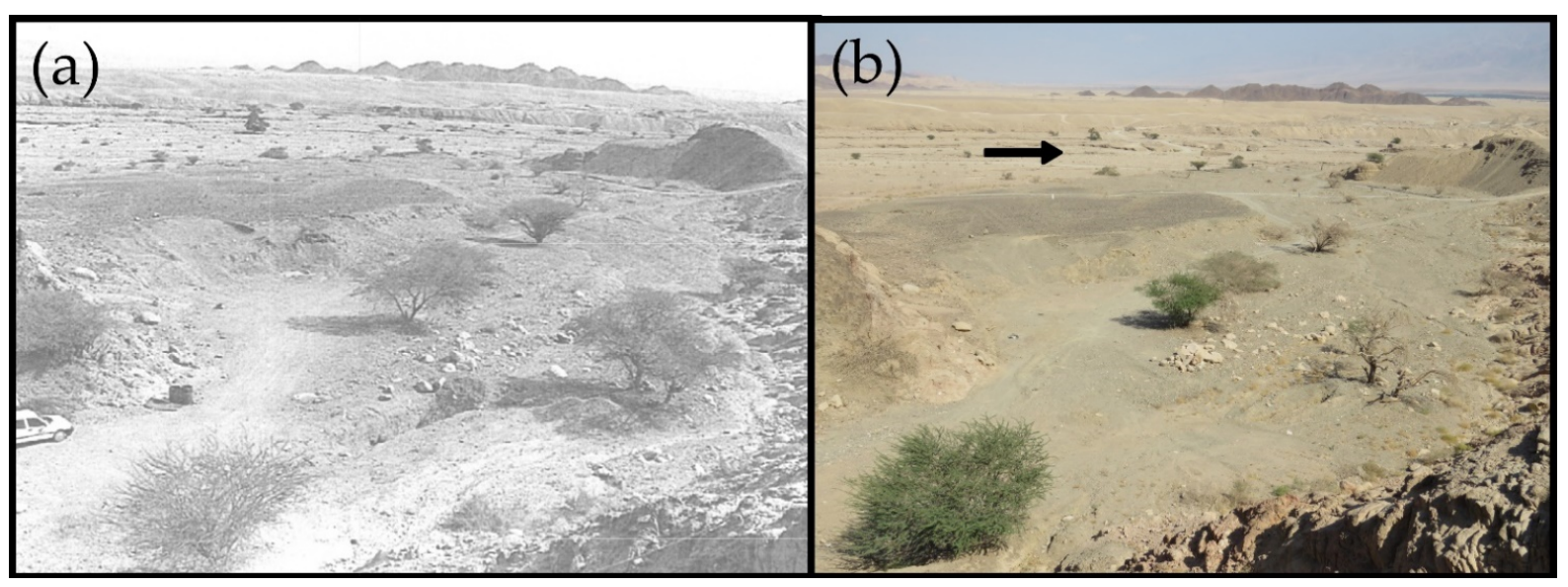

Figure 2. Nahal Yael's alluvial fan as shown in photographs taken from the dam, looking northwest: (a) Nahal Yael alluvial fan as seen in 1994, after Bendavid-Novak and Schick [14] with permission; (b) Photograph of the same location taken in 2017. Nahal Roded's main channel is seen in the distance (black arrow). 


\subsection{Field Work and Data Analysis}

Long-term precipitation data (measured in Eilat, $4 \mathrm{~km}$ from the study site) was obtained from the Israel Meteorological Service [36]. We analyzed changes in precipitation levels during three periods, including 1972-1994 (before the long-term drought episode commenced), 1995-2009 (the drought episode), and 2010-2020 (following the end of the drought episode).

Long-term dynamics in the acacia population were determined by assessing individual trees in 1972,1994, and 2017, and by summing up 45 years of changes at individual and population levels. Data collection in 1972 and 1994 was conducted and published by Bendavid-Novak and Schick [14]. We collected data in the field during 2017 and analyzed the entire data for the three temporal sets. In 1972, the state of acacia trees was assessed using aerial photos (with an approximate resolution of 1:1000) five years prior to dam construction. In 1994, the Acacia population was surveyed in the field, examining mortality and recruitment rates 17 years after dam establishment in Nahal Yael [14]. The findings of Bendavid-Novak and Schick [14] study indicate that the construction of the dam caused mortality of Acacia in Nahal Yael alluvial fan. In 2017, Acacia populations in Nahal Yael and Nahal Naomi were monitored to assess the effects of drought and dam construction. Combining the results obtained in 2017 with those obtained in 1972 and 1994 by BendavidNovak and Schick [14] allowed us to assess changes at the individual and population levels over a 45-year period (1972-2017).

Between November 2017 and March 2018, we conducted a field survey in the alluvial fans of Nahal Yael and Nahal Naomi, and monitored all existing acacia individuals, whether alive or dead (the smallest tree, $0.2 \mathrm{~m}$ high, $1 \mathrm{~m}$ canopy diameter, is estimated to be at least two years old). The surveyed area was restricted to the area assessed by Bendavid-Novak and Schick [14]. For each individual, we recorded the location both with GPS (to resolution level of one meter) and manually with high resolution aerial photo, species (A. raddiana vs. $A$. tortilis), and dimensions (canopy's diameter and height). Dead trees were assigned a relative value for their state of preservation: 0 for a fallen tree; 1 for a standing tree with a broken canopy; and 2 for a standing tree with well-preserved canopy. acacia distance from the mountain toeslopes was also measured (using measure tape). Bendavid-Novak and Schick [14] suggested that the

Spatial data analysis was performed using GIS tools (ArcGIS10) and detailed examination on site. Three maps were compared to build a life history schema for each individual: (i) the distribution map published in Bendavid-Novak and Schick (Figure 4 in [14]); (ii) the original aerial photo taken in 1972; and (iii) an aerial photo containing tree location and conditions at 2017. After identifying the location of each tree, the results were validated in the field.

The life history for each individual tree included the year the tree was first reported, and in the event of death, the year death was reported. In addition, we divided the entire population into six groups, according to the following categories: (1) trees reported live both in the 1972 and 2017 surveys; (2) trees reported live in 1972 and dead in 2017; (3) trees reported live in 1972 and dead in 1994; (4) trees reported live in 1994 and live in 2017; (5) trees reported live in 1994 and dead in 2017; and (6) trees first reported live in 2017 survey (Figure 4a in [14]). After dividing the entire population into groups of individuals with a similar life history, we calculated the total and the average yearly percentage of mortality and recruitment, in Nahal Naomi and Nahal Yael during the two periods of 1972-1994 and 1994-2017. Using data on yearly mortality and recruitment rates, we calculated the net change per year $\left(\right.$ mortality rate + recruitment rate $=$ net change $\left(\%\right.$ year $\left.\left.{ }^{-1}\right)\right)$, aimed at calculating the approximate change in population size over time.

All trees recorded in 1997 (dead and alive) were found at different levels of conservation. In addition, new recruits that were added to the population after 1994 were also found in 2017. We found and recorded all individuals that were documented in 1994 by Bendavid-Novak and Schick [14]. We found a small discrepancy between the results reported by Bendavid-Novak and Schick [14] in Figure 4, p. 346 (distribution map of live 
and dead trees on the alluvial fans in 1994) and their Table 1, p. 345 (summary data of Acacia population survey in the alluvial fans). We used the data shown in Bendavid-Novak and Schick's Figure 4.

Statistical analysis were carried out using the Statistica $13^{\circledR}$ statistical software (Statsoft Inc, Tulsa, OK, USA). 'Annual rainfall' and 'tree distances from the slopes' datasets were first tested for normality (Kolmogorov-Smirnov test) and homogeneity of variances (Levene's test). For this parametric data, differences were tested using one-way ANOVA (annual rainfall), two-way ANOVA (tree distances from the slopes) and a Tukey HSD test for post hoc comparisons. Differences of dead, alive, recruited trees, and species counting between the sites and years were tested by $2 \times 2$ contingency table using Fisher's exact test (two tailed).

\section{Results}

Mean annual rainfall between 1972 and 2020 was $24.1 \mathrm{~mm} \mathrm{year}^{-1}$ (Figure 3), however annual variability was high and ranged between 2-58 $\mathrm{mm}^{-1}$ year $^{-1}$. Between 1972-1994, before the drought period, the mean annual rainfall was $28.9 \pm 2.8 \mathrm{~mm}^{-1}$ year $^{-1}$ (mean $\pm \mathrm{SE}$ ). In the drought period of 1995-2009, the mean decreased to $13.9 \pm 2.5 \mathrm{~mm}_{\text {year }}{ }^{-1}$. Between 2010-2020, the mean increased to $28.2 \pm 5.6 \mathrm{~mm}_{\text {year }}{ }^{-1}$. Analysis of rainfall data for these three periods revealed a significant $(p=0.0052)$ difference, with values being significantly greater for 1972-1994 $(p=0.006)$ and 2010-2020 $(p=0.032)$ than for 1995-2009.

(a)

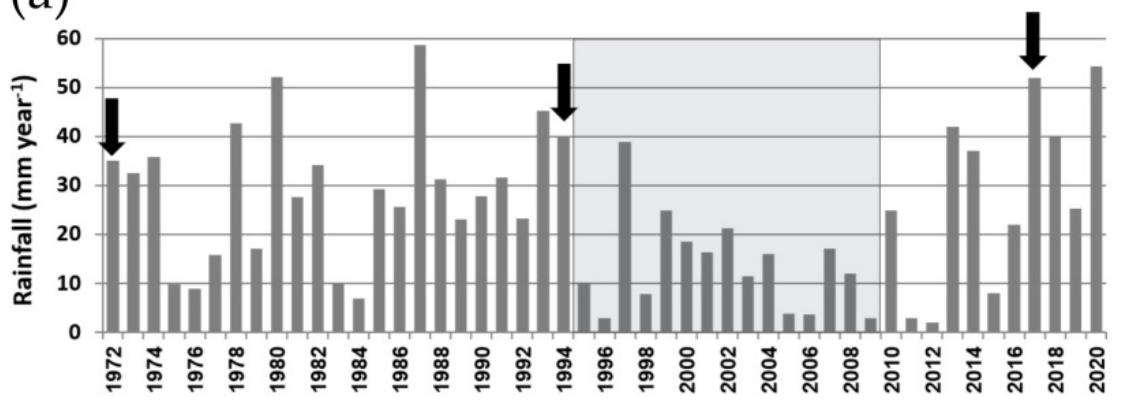

(b)

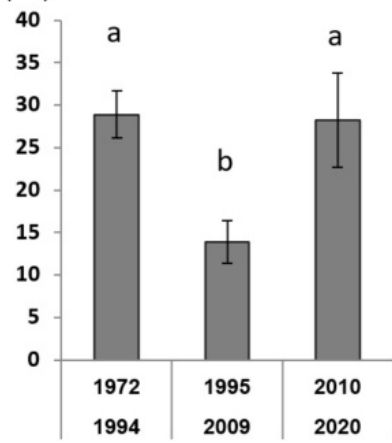

Figure 3. Annual rainfall in Eilat according to the Israel Meteorological Service [36]: (a) Throughout the duration of the study (the drought period is marked in gray); and (b) Mean ( \pm SE) of three periods, 1972-1994 (before the commence of the long-term drought episode), 1995-2009 (the drought episode) and 2010-2020 (following the end of the drought episode). The letters above the bars represent significant differences $(p<0.05)$ between the years. Black arrows indicate the years in which the tree surveys were conducted.

The survey conducted during 2017 revealed high mortalities both in Nahal Naomi and Nahal Yael. In Nahal Naomi, 52 acacia trees were recorded, including 18 live and 34 dead individuals (65\% mortality). In Nahal Yael, 27 acacia trees were found, of which eight were alive and 19 dead (70\% mortality). Although these numbers seem to show a similar trend of decline, unique patterns can be detected for the two wadis when looking at higher temporal resolution, which takes the drought episode that occurred between 1995-2009 into account (Figure 4a,b).

When examining the mortality changes in the two sites (Figure 4b) during 1972-1994 (the relatively rainy period), it is evident the acacia population in Nahal Yael (also affected by the dam construction) had higher mortalities $(p=0.034)$ than the nearby Nahal Naomi population, with 11 deaths in Nahal Yael (out of 24) compared to five deaths in Nahal Naomi (out of 31). Between 1994-2017 (during and following the drought episode), the populations of Yael and Naomi experienced similar mortality ratios, with no significant difference between the two sites. Looking at the changes before and after the drought 
period in each site, mortalities in Nahal Naomi increased significantly $(p<0.0001)$ from 5 deaths (out of 31, during 1972-1994) to 32 deaths (out of 42, during 1994-2017). In Nahal Yael, mortalities remained high both before (a 33.3\% decrease) and after (a 50\% decrease) the drought period $(p=1)$.

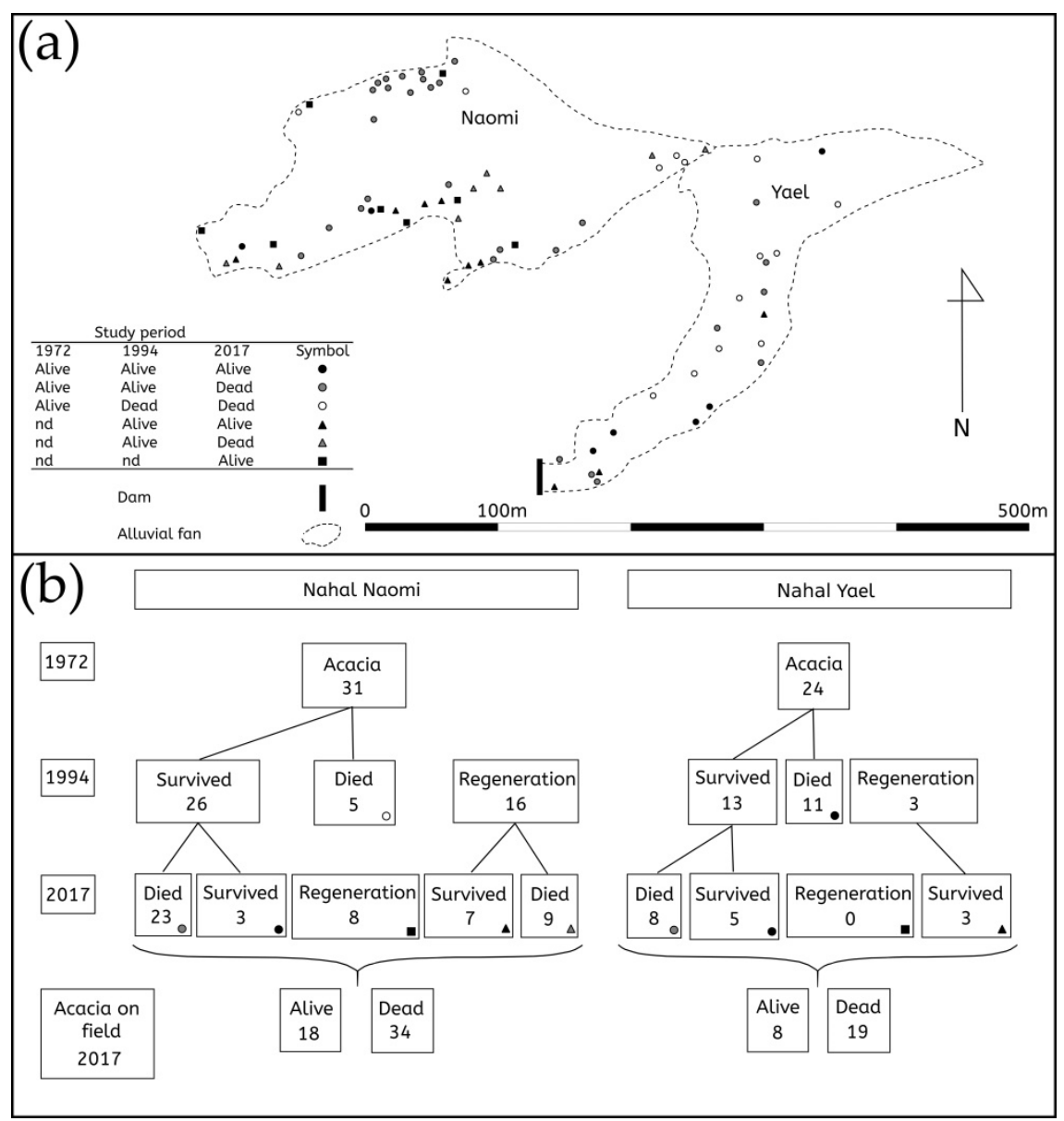

Figure 4. Population dynamics of acacia: (a) Distribution map of trees on the alluvial fans of Nahal Naomi (on the left) and Nahal Yael (on the right). Each tree is marked by symbols according to its life history schema; (b) Flowchart summarizes the number of trees with a similar life history schema. The symbols in panels a and b represent: (1) trees reported live both in the 1972 and 2017 surveys (black circle); (2) trees reported live in 1972 and dead in 2017 (gray circle); (3) trees reported live in 1972 and dead in 1994 (white circle); (4) trees reported live in 1994 and live in 2017 (black triangle); (5) trees reported live in 1994 and dead in 2017 (gray triangle); and (6) trees first reported live in 2017 survey (black square).

Although both populations experienced high mortality, recruitment of new individuals were detected at both sites (Figure 4b). During the rainy period (1972-1994), populations in Nahal Naomi increased by $35.5 \%$ (from 31 to 42 live individuals), of which 16 were new recruits. During and following the drought period (1994-2017), this population had 8 new recruits, with an average height of $0.9 \pm 0.2 \mathrm{~m}$ (Table 1). Overall, the number of recruits was similar during these two periods $(p=0.77)$. In Nahal Yael, recruitment was found to be very low. During the rainy period (1972-1994), three new recruits were recorded, while during and following the drought period (1994-2017), this population had no recruitment at all. The number of recruits at Nahal Naomi and Nahal Yael was not significantly different during the rainy period. During and following the drought period (1994-2017), Nahal Yael had significantly less recruits than Nahal Naomi $(p=0.03)$. 
Table 1. Acacia size (average height and canopy area \pm SE) in 2017 survey according to three age groups (from both sites): trees reported alive both in the 1972 and 2017 surveys ( $>45$ year old), trees reported alive in 1994 and 2017 (22-45 year old trees), trees first reported alive in 2017 survey $(<22$ year old $)$.

\begin{tabular}{lccc}
\hline & $>$ 45 Years Old & 45-22 Years Old & $<22$ Years Old \\
\cline { 2 - 4 } & $\mathbf{( N = 8 )}$ & $\mathbf{( N = 1 0 )}$ & $(\mathbf{N}=\mathbf{8})$ \\
\hline Average height $(\mathrm{m})$ & $4.1 \pm 0.5$ & $2.7 \pm 0.4$ & $0.9 \pm 0.2$ \\
Average canopy area $\left(\mathrm{m}^{2}\right)$ & $23.7 \pm 7.6$ & $15.6 \pm 7.3$ & $1.8 \pm 0.7$ \\
\hline
\end{tabular}

The three recruited individuals recorded in 1994 in Nahal Yael were found alive in 2017, i.e., they survived the drought period (Figure 4b). Also, seven out of the sixteen new recruits recorded in 1994 in Nahal Naomi survived the drought period and were found alive in 2017. Altogether, young trees in Nahal Yael and Nahal Naomi survived the drought period in higher numbers $(p=0.02)$ than older trees that were recorded alive in 1972 in the alluvial fans.

We noticed that many of the remaining living trees in Nahal Yael and Nahal Naomi grow near the mountains' rocky toeslope (Figure 4a). Speculating that the proximity to toeslopes gives an advantage to trees during drought periods, we tested the distance from the slopes of living and dead trees at both alluvial fans and found that living trees are significantly closer to the slopes than the dead trees $(p=0.018)$. In Nahal Naomi, the distance of living and dead trees from the toeslopes is $11.7 \pm 2(n=18)$ and $17.2 \pm 2.8$ $(n=29)$, respectively. In Nahal Yael, the distance was $8 \pm 2.3(n=6)$ for living and $24.6 \pm 5.7$ $(n=18)$ for dead trees, respectively. In this analysis, we excluded two individuals that are not located directly on the alluvial fan. One located directly on rocky slope and the second on boundary line between Nahal Yael alluvial fan and Nahal Roded channel.

Due to variations in preservation state of dead trees, we succeeded in identifying Acacia species for ca. $70 \%(N=56)$ of the trees. Overall, $75 \%$ of acacia are $A$. tortilis and $25 \%$ are $A$. raddiana, evenly distributed between the sites. Among these individuals, $64 \%$ of the $A$. tortilis and $57 \%$ of the $A$. raddiana were found dead during 2017 (with no significant variation between them, $p=0.75)$. All individuals recorded as dead in 1994 were found again in 2017; 37.5\% of them were still standing and had some canopy (see Figure 5a), $18.8 \%$ were standing without canopy, and $43.8 \%$ were fallen trees at various levels of decay.

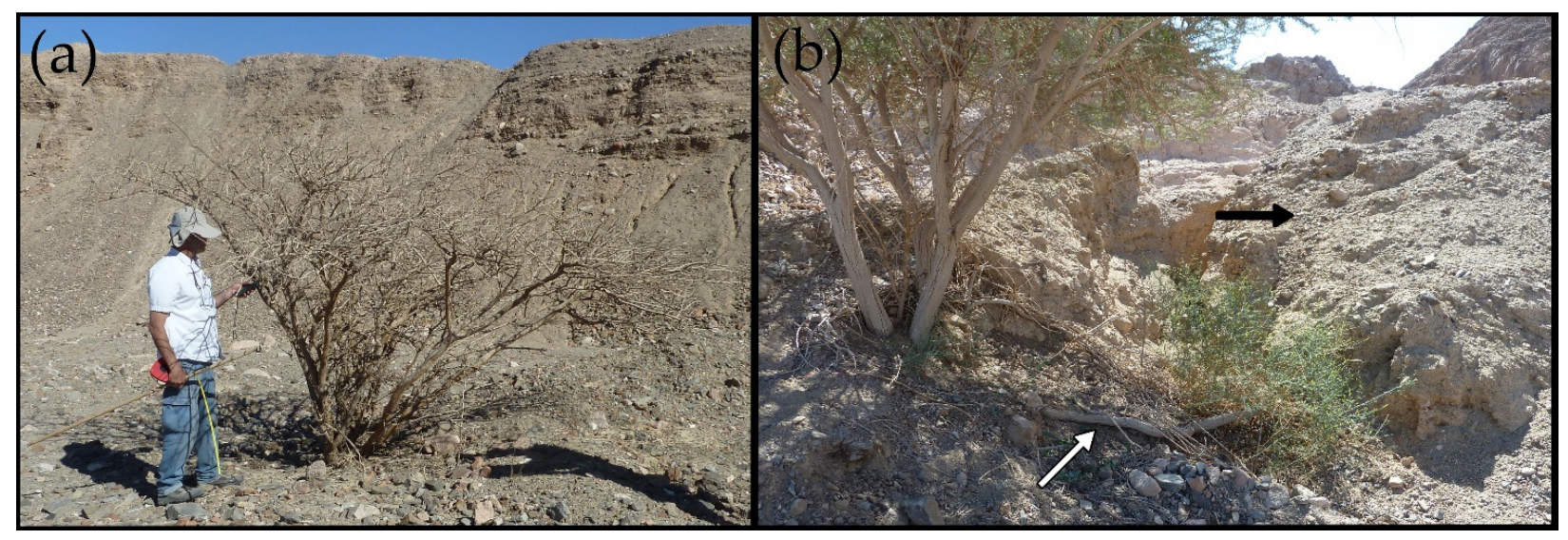

Figure 5. Acacia on the alluvial fan of Nahal Yael: (a) Well-preserved dead acacia reported to be dead in 1994, standing more than 25 years after death with a preserved canopy; (b) acacia roots (white arrow) penetrate the dam at Nahal Yael (black arrow) toward the reservoir area.

The total percentage of mortality and recruitment in Nahal Naomi and Nahal Yael during 1972-1994 and 1994-2017 was used to calculate the average percentage rates of mortality and recruitment per year (summarize in Table 2). Calculating the average rate 
of mortality and recruitment per year enabled us to standardize the total percentage with respect to the duration of the measurement. Overall, between 1972-1994, the acacia population in Nahal Naomi increased by $35.5 \%$, with low mortality $\left(17 \%\right.$, or $0.7 \%$ year $^{-1}$, Table 2$)$ and high recruitment $\left(51 \%\right.$, or $2.3 \%$ year $^{-1}$ ) rates. The relatively fast recruitment, coupled with low mortality, increased population size over that period. Between 1994-2017, the population suffered high mortality $\left(76 \%, 3.2 \%\right.$ year $\left.^{-1}\right)$ and lower recruitment $(19 \%, 0.8 \%$ year $^{-1}$ ) rates, compared to the pre-drought period (Table 2), decreasing population size.

Table 2. Mortalities and recruitment in Nahal Naomi and Nahal Yael during 1972-1994 and 1994-2017, as a total percentage, percentage per year, and net change per year.

\begin{tabular}{|c|c|c|c|c|c|}
\hline & & \multicolumn{2}{|c|}{ Nahal Naomi } & \multicolumn{2}{|c|}{ Nahal Yael } \\
\hline & & Mortality & Recruitment & Mortality & Recruitment \\
\hline 1972-1994 & Total percentage & $17 \%$ & $51 \%$ & $46 \%$ & $12 \%$ \\
\hline \multirow{2}{*}{ Bendavid-Novak and Schick [14] } & Percentage per year & $0.7 \% \mathrm{y}^{-1}$ & $2.3 \% \mathrm{y}^{-1}$ & $2 \% y^{-1}$ & $0.5 \% \mathrm{y}^{-1}$ \\
\hline & Net change per year & \multicolumn{2}{|c|}{$1.5 \% \mathrm{y}^{-1}$} & \multicolumn{2}{|c|}{$-1.5 \% \mathrm{y}^{-1}$} \\
\hline \multirow[t]{3}{*}{ 1994-2017 } & Total percentage & $76 \%$ & $19 \%$ & $50 \%$ & $0 \%$ \\
\hline & Percentage per year & $3.2 \% \mathrm{y}^{-1}$ & $0.8 \% \mathrm{y}^{-1}$ & $2 \% y^{-1}$ & $0 \% y^{-1}$ \\
\hline & Net change per year & \multicolumn{2}{|c|}{$-2.4 \% \mathrm{y}^{-1}$} & \multicolumn{2}{|c|}{$-2 \% y^{-1}$} \\
\hline
\end{tabular}

In the Nahal Yael alluvial fan, the acacia population has faced constant decline. Between 1972 and 1994, mortality rates reached 46\% (2\% year ${ }^{-1}$, Table 2$)$ and only three Acacia recruits were recorded (12\% recruitments, or $0.6 \%$ year $^{-1}$ ). Between 1994 and 2017, the population experienced an additional decline, with $50 \%$ mortality $\left(2 \%\right.$ year $\left.{ }^{-1}\right)$ and no recruitment.

Using data on mortality and recruitment rates (as calculated in Table 2 ; \% year ${ }^{-1}$ ), we further calculated the net change per year (mortality rate + recruitment rate $=$ net change $\left(\%\right.$ year $\left.\left.{ }^{-1}\right)\right)$. When mortality rate is higher than the recruitment rate, this value is negative, and when recruitment rate is higher than mortality rate, this value is positive. Accordingly, the net change in Nahal Naomi was $1.6 \%$ year $^{-1}$ in the pre-drought period (1972-1994) and $-2.5 \%$ year $^{-1}$ between 1994 and 2017, which pertains to the long-term drought period. In Nahal Yael, the net change between 1972 and 1994 was $-1.4 \%$ year ${ }^{-1}$. During the period of 1994-2017, the net change further decreased to $-2.0 \%$ year $^{-1}$, due to the combined effect of the dam (that was constructed in 1977) and drought.

We then calculated the approximate change in population size, given a net change ranging between $+1.5 \%$ to $-2.5 \%$ year $^{-1}$, after 10,20 and 30 years (Table 3 ). Given a net change of $-2.5 \%$ year $^{-1}$ (as calculated in Nahal Naomi between 1994 and 2017), the population would decrease to $75 \%$ of its original size after 10 years, and to $50 \%$ after 20 years. In case of population growth such as measured in Nahal Naomi between 1972-1994 (ca. $1.5 \%$ year $^{-1}$ ), the population would increase to $115 \%$ of its original size after 10 years, and to $130 \%$ after 20 years.

Table 3. Expected change in population size under different net change values. Rate of change measured in Nahal Naomi and Nahal Yael are marked in asterisks $\left(^{*}\right)$.

\begin{tabular}{|c|c|c|c|c|c|c|c|c|c|c|}
\hline \multicolumn{2}{|c|}{ Rate of Change ( $\%$ year $\left.^{-1}\right)$} & $-2.5 *$ & $-2 *$ & $-1.5 *$ & -1 & -0.5 & 0 & 0.5 & 1 & 1.5 * \\
\hline \multirow{3}{*}{$\begin{array}{c}\text { Change in } \\
\text { population size } \\
(\%)\end{array}$} & After $10 \mathrm{y}$ & 75 & 80 & 85 & 90 & 95 & 100 & 105 & 110 & 115 \\
\hline & After $20 \mathrm{y}$ & 50 & 60 & 70 & 80 & 90 & 100 & 110 & 120 & 130 \\
\hline & After $30 \mathrm{y}$ & 25 & 40 & 55 & 70 & 85 & 100 & 115 & 130 & 145 \\
\hline
\end{tabular}

\section{Discussion}

Assessment of acacia distribution and health throughout the Arava region revealed that acacia populations are affected by climatic changes [25]. Yet, it has been proposed that anthropogenic activities have also significantly impacted these acacia populations $[3,12,13,30]$. 
Despite these studies, the combined effect of natural and anthropogenic stressors on mortality and recruitment rates of acacia populations is not well understood.

The general mortality ratio of acacia populations in the pre-drought period (1972-1994) measured in seven undisturbed sites in the southern Arava Valley-was $12.3 \pm 7 \%$ (see Table 4). This value is similar to the mortality ratio in the undisturbed Nahal Naomi $(11.9 \%)$. The much higher mortality ratio $(40.7 \%)$ in Nahal Yael during this period is attributed to the dam's construction and exemplifies the anthropogenic impact. The effect of dams is similar to that of berms (that are widely used to protect infrastructures from runoff), and therefore has broader implications (e.g., [12]). In both cases, the anthropogenic disturbances interfere with the natural hydrological system and prevent runoff from reaching downstream vegetation. When analyzing available data for the post-drought period (2010-2017) in other sites across the region, an increase in mean mortality ratios compared to the pre-drought period is evident ( $44.2 \pm 18 \%, N=7$; Table 4$)$. The mortality ratio in Nahal Naomi is quite high $(65.4 \%)$, but not much different from data published for the adjacent Nahal Roded (55-60\%), nor from other sites located northward in the Arava (e.g., $72 \%$ in Nahal Ketura; [15]). Overall, our results are in agreement with other data from the region (Table 4).

Table 4. Acacia mortality in different sites across the Eilat region, before and after the drought episode of 1995-2009 (\% of dead individuals out of the total number of trees).

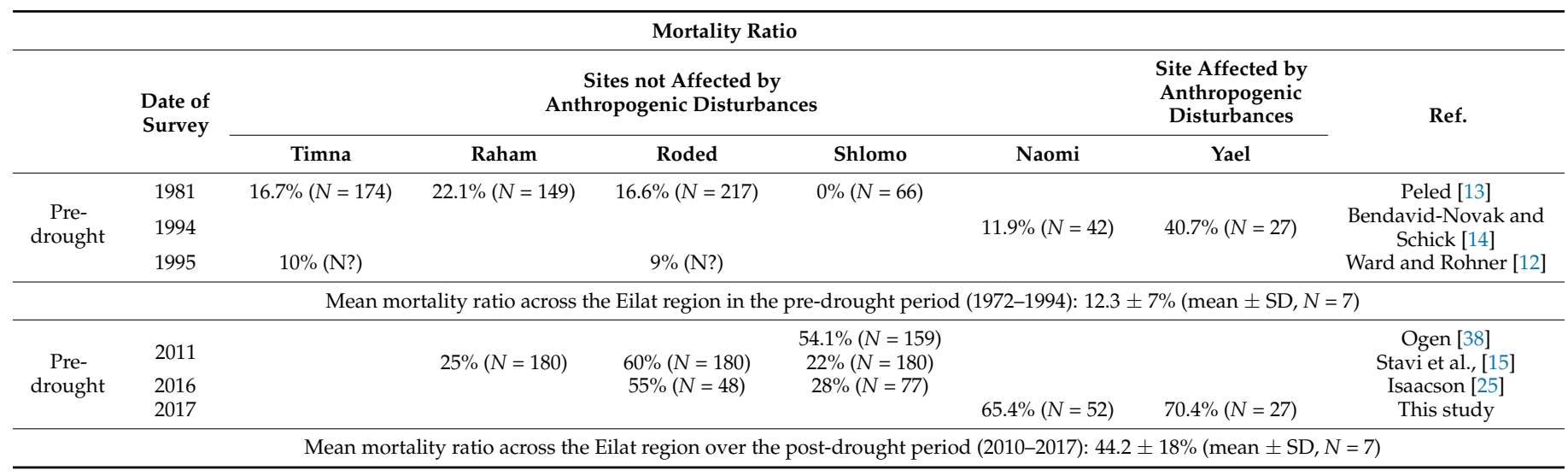

Inter-site variability in acacia mortality reported for the Arava Valley is affected by several factors, such as soil properties [39,40], fluvial processes [20,25,40], latitude [15], and anthropogenic disturbances [12-14,30,32]. While the effect of watershed size is still unclear [22,25], very few mortalities were documented in the Arava Sabkhas (discharge playas), probably due to their characteristic high groundwater level [25]. Tree mortality assessments in the field indicate the current state of a population and are easily visible. However, actual changes in population size are difficult to evaluate. Because dead trees remain standing on-site for a long period of time, the mortality percentage increases constantly, obscuring true changes in population dynamics. In the present work, we were able to better quantify population dynamics by monitoring the same individuals over a period of 45 years. In addition, we were able to quantify recruitment rates, a more challenging measurement.

Finally, we determined a useful term that takes into account both mortality and annual rates of recruitment- the annual net change. Our results indicate that the net change in Acacia population in the southern Arava ranged between $+1.5 \%$ to $-2.5 \%$ year $^{-1}$ (Table 2). This range of average net changes provides an estimation of the expected change in population sized over long periods (Table 3 ). This calculation can be used as a tool that helps to predict an approximate change in population size over time for populations located at ephemeral channels and alluvial fans. Since mortality and recruitment are not linear 
processes but occur in waves, the average net change is more applicable in understanding processes over long periods.

Assessments of acacia populations dynamics in Nahal Naomi over 45 years (1972-2017) revealed the severe impact of the drought period between 1995-2009. The alluvial fan of Nahal Naomi is located in a nature reserve and has experienced minimal human impact. Changes in acacia mortality over the temporal axis fit well with the regional rainfall records (Figure 3). Between 1972-1994, the average annual rainfall was above average, and the population size increased, with low mortality and high recruitment (Table 2). Between 1994-2017, during and following the drought period, the population reduced in size due to high mortality. In the nearby Nahal Roded, Isaacson [25] reported on annual mortality rate of 3.8\% year ${ }^{-1}$ between 2001-2016 (during and after the drought), which is similar to the mortality rate in Nahal Naomi during 1994-2017 (3.2\% year $\left.{ }^{-1}\right)$ (Table 2). Of the 31 alive trees in Nahal Naomi in 1972, only three survived until 2017. Since acacia is a long-living tree genus that can live 200-600 years [20,21], this mass mortality seems highly exceptional. The high mortality during the drought was followed by high recruitment. The average small size of the individuals recruited in Nahal Naomi between 1994-2017 (Table 1) indicate that they emerged after the drought episode ended (2010).

In the alluvial fan of Nahal Yael, the acacia population has faced constant decline since the wadi outlet was dammed in 1977. Between 1972-1994 (the relatively rainy period) the population experienced high mortality and low recruitment. Between 1994-2017, mortality remained high and no recruitment took place. In Nahal Yael, the acacia population has been therefore co-affected by decreased precipitations and anthropogenic disturbance.

The new recruited individuals in Nahal Naomi and Nahal Yael had higher survival rates during the drought period than the older trees. This indicates that in terms of survivability, new recruits have an advantage over older trees. A possible explanation that needs to be further addressed is that new recruits settle near recent and relatively active ephemeral stream channels. It has been shown that the dynamic nature of the alluvial fans' braided system decreases the frequency of floods in other parts of the alluvial fans, where older trees exist [17].

As suggested by Bendavid-Novak and Schick [14] during drought periods, the close proximity of acacia trees to rocky toeslopes seems to be an advantage, and acacia located near the toeslopes have higher survival rates than trees located in the middle of the alluvial fan (Figure 4a). This is explained by the potentially higher runoff ratio during small rain events that do not form a flash floods but do generate runoff from the rocky hillslopes.

A close look at the acacia distribution map (Figure 4a) shows that a live tree in the alluvial fan of Nahal Yael is adjacent to the dam. This individual tree extends its roots to the reservoir upstream of the dam (as shown in Figure 5b). This observation is in accord with Peled [13], who reported that acacia roots in the southern Arava wadis extend their roots towards water sources, usually upstream. It is therefore can be assumed that trees can reach a nearby water source.

Indications of population recovery in Nahal Naomi, as opposed to the constant population decline in Nahal Yael, support the growing consent that acacia trees in ephemeral channels and alluvial fans rely on surface water and on moisture found in relatively shallow soil layers, which originate from floods and not from underground aquifers [14,32,41,42].

Another worthy observation is the significance of the long standing period of dead acacias. The trunks of all the recorded dead acacia in 1994 [14] were still standing in 2017. Out of these trees, $37.5 \%$ preserved their canopy for at least 25 years (Figure $5 a$ ). Ward and Rohner [12] estimated that acacias in the Arava region remain standing for an average of 10 years after death. Our findings suggest that this is an underestimation. Our findings are closer to those of Isaacson [25], who reported that acacia can stand for at least 15 years after death in the Arava Valley. 


\section{Conclusions}

This study evaluated the dynamics in acacia populations during a period of 45 years (1972-2017) in two small alluvial fans in the hyper-arid Arava Valley. The results quantified the combined effects of natural change (a long-term drought period) and anthropogenic disturbance (dam construction) on acacia mortality and recruitment. Overall, both populations experienced a sharp decline in numbers during the drought. Yet, since the drought ended, the population located in a nature reserve rapidly began to recover, while the population experiencing anthropogenic interferences has not shown signs of recovery, and new recruits have not emerged. By examining tree characteristics such as location, species, age, and state of preservation of dead trees, we were able to identify factors that influence tree mortality. Trees that better survived the drought periods are the younger individuals and those in closer proximity to mountains' rocky toeslopes.

Author Contributions: Conceptualization, R.A.-Z. and I.A.; methodology, R.A.-Z. and I.A.; software, R.S.-T.; investigation, Y.S. and I.A.; data curation, R.A.-Z. and I.A.; writing-original draft preparation, R.A.-Z. and I.A.; writing-review and editing, R.A.-Z. and I.S.; visualization, R.S.-T.; funding acquisition, R.A.-Z. All authors have read and agreed to the published version of the manuscript.

Funding: This research was funded by the Arava Drainage Authority (Israel) and the Ministry of Science \& Technology, Israel, grant number alona17525.

Institutional Review Board Statement: Not applicable.

Informed Consent Statement: Not applicable.

Data Availability Statement: The data presented in this study are available on request from the corresponding author.

Acknowledgments: We thank Judith Lekach for kindly providing us the aerial photos of Nahal Yael and Nahal Naomi, which were previously used by Bendavid-Novak and Schick [14]. Also, we are grateful to Sivan Isaacson, Jonathan B. Laronne and Jessica Schäckermann, who read the manuscript and offered valuable comments and to Michelle Finzi for carefully editing this manuscript. In addition, we would like to thank the Acacia Research Center for supporting this research.

Conflicts of Interest: The authors declare no conflict of interest. The funders had no role in the design of the study; in the collection, analysis, or interpretation of data; in the writing of the manuscript, or in the decision to publish the results.

\section{References}

1. Andersen, G.L. Vegetation and management regime continuity in the cultural landscape of the Eastern Desert. In The History of the Peoples of the Eastern Desert; Barnard, H., Duistermaat, K., Eds.; Cotsen Institute of Archaeology University of California: Los Angeles, CA, USA, 2012; pp. 126-139.

2. Andersen, G.L.; Krzywinski, K.; Talib, M.; Saadallah, A.E.M.; Hobbs, J.J.; Pierce, R.H. Traditional nomadic tending of trees in the Red Sea Hills. J. Arid Environ. 2014, 106, 36-44. [CrossRef]

3. Andersen, G.L.; Krzywinski, K. Mortality, recruitment and change of desert tree populations in a hyper-arid environment. PLoS ONE 2007, 2, e208. [CrossRef]

4. Chaudhary, S.A. Destructions of Acacia woodlands and juniper forests in Asia and eastern Africa. Pak. J. Bot. 2010, 42, $259-266$.

5. Dean, W.R.J.; Milton, S.J.; Jeltsch, F. Large trees, fertile islands, and birds in arid savanna. J. Arid Environ. 1999, 41, 61-78. [CrossRef]

6. Hackett, T.D.; Korine, C.; Holderied, M.W. The importance of Acacia trees for insectivorous bats and arthropods in the Arava Desert. PLoS ONE 2013, 8, e52999. [CrossRef]

7. Hobbs, J.J.; Krzywinski, K.; Andersen, G.L.; Talib, M.; Pierce, R.H.; Saadallah, A.E.M. Acacia trees on the cultural landscapes of the Red Sea Hills. Biodivers. Conserv. 2014, 23, 2923-2943. [CrossRef]

8. Krzywinski, K.; Pierce, R.H. Deserting the Desert, A Threatened Cultural Landscape between the Nile and the Sea; Alvheim og Eide Akademisk Forlag: Bergen, Norway, 2001.

9. Munzbergova, Z.; Ward, D. Acacia trees as keystone species in the Negev desert ecosystems. J. Veg. Sci. 2002, 13, 227-236. [CrossRef]

10. Wickens, G.E.; Seif El Din, A.G.; Sita, G.; Nahal, I. Role of Acacia Species in the Rural Economy of Dry Africa and the Near East; FAO Conservation Guide 27: Rome, Italy, 1995. 
11. Huang, J.; Ji, M.; Xie, Y.; Wang, S.; He, Y.; Ran, J. Global semi-arid climate change over last 60 years. Clim. Dyn. 2016, 46, 1131-1150. [CrossRef]

12. Ward, D.; Rohner, C. Anthropogenic causes of high mortality and low recruitment in three Acacia tree taxa in the Negev desert, Israel. Biodivers. Conserv. 1997, 6, 877-893. [CrossRef]

13. Peled, Y. Mortality of Acacia Trees in the Southern Arava. Master's Thesis, Hebrew University, Rehovot, Israel, 1988.

14. Bendavid-Novak, H.; Schick, A.P. The response of Acacia tree populations on small alluvial fans to changes in the hydrological regime: Southern Negev Desert, Israel. Catena 1997, 29, 341-351. [CrossRef]

15. Stavi, I.; Silver, M.; Avni, Y. Latitude, basin size, and microhabitat effects on the viability of Acacia trees in the Negev and Arava, Israel. Catena 2014, 114, 149-156. [CrossRef]

16. Lahav-Ginott, S.; Kadmon, R.; Gersani, M. Evaluating the viability of Acacia populations in the Negev Desert: A remote sensing approach. Biol. Conserv. 2001, 98, 127-137. [CrossRef]

17. Isaacson, S.; Ephrath, J.E.; Rachmilevitch, S.; Maman, S.; Ginat, H.; Blumberg, D.G. Long and short term population dynamics of acacia trees via remote sensing and spatial analysis: Case study in the southern Negev Desert. Remote Sens. Environ. 2017, 198, 95-104. [CrossRef]

18. Perleberg, A.; Ron, M.; Ramon, U. Acacia Survey in the Arava; Hakeren Hakayemet LeIsrael and Open Landscape Institute: Tel Aviv, Israel, 2013.

19. Moustakas, A.; Wiegand, K.; Getzin, S.; Ward, D.; Meyer, K.M.; Guenther, M.; Mueller, K.1.-H. Spacing patterns of an Acacia tree in the Kalahari over a 61-year period: How clumped becomes regular and vice versa. Acta Oecol. 2008, 33, 355-364. [CrossRef]

20. Andersen, G.L.; Krzywinski, K. Longevity and growth of Acacia tortilis; insights from ${ }^{14} \mathrm{C}$ content and anatomy of wood. BMC Ecol. 2007, 7, 4. [CrossRef]

21. Goslar, T.; Andersen, G.; Krzywinski, K.; Czernik, J. Radiocarbon determination of past growth rates of living Acacia tortilis trees from two arid sites in Eastern Sahara. Radiocarbon 2013, 55, 1683-1692. [CrossRef]

22. Stavi, I.; Shem-Tov, R.; Shlomi, Y.; Bel, G.; Yizhaq, H. Recruitment and decay rate of Acacia seedlings in the hyper-arid Arava Valley, Israel. Catena 2015, 131, 14-21. [CrossRef]

23. Wiegand, K.; Ward, D.; Thulke, H.-H.; Jeltsch, F. From snapshot information to long-term population dynamics of Acacias by a simulation model. Plant. Ecol. 2000, 150, 97-114. [CrossRef]

24. Wiegand, K.; Jeltsch, F.; Ward, D. Minimum recruitment frequency in plants with episodic recruitment. Oecologia 2004, 141, 363-372. [CrossRef]

25. Isaacson, S. Monitoring Drought Stress in Acacia Trees in Hyper-Arid Zones: Geo-Ecophysiology Aspects. Ph.D. Thesis, Ben-Gurion University of the Negev, Beer Sheva, Israel, 2017.

26. Andersen, G.L.; Krzywinski, K.; Gjessing, H.K.; Pierce, R.H. Seed viability and germination success of Acacia tortilis along land-use and aridity gradients in the Eastern Sahara. Ecol. Evol. 2016, 6, 256-266. [CrossRef]

27. Blanco, J.; Genin, D.; Carrière, S. The influence of Saharan agro-pastoralism on the structure and dynamics of acacia stands. Agric. Ecosyst. Environ. 2015, 213, 21-31. [CrossRef]

28. Ginat, H.; Shlomi, Y.; Batarseh, S.; Vogel, J. Reduction in precipitation levels in the Arava Valley (Southern Israel and Jordan), 1949-2009. J. Dead-Sea Arava Res. 2011, 1, 1-7.

29. Katz, T.; Ginat, H.; Eyal, G.; Steiner, Z.; Braun, Y.; Shalev, S.; Goodman-Tchernov, B.N. Desert flash floods form hyperpycnal flows in the coral-rich Gulf of Aqaba, Red Sea. Earth Planet. Sci. Lett. 2015, 417, 87-98. [CrossRef]

30. Ashkenazi, S. Acacia Trees in the Negev and Arava, Isral-A Review Following Reported Large-Scale Mortality; Hakeren Hakayemet LeIsrael: Jerusalem, Israel, 1995.

31. Groner, E.; Rapaport, A.; Segev, N.; Ragolsky, G.; Nelvitsky, R.; Alexander, K.; Rabinowitz, O.; Grunfeld, M.; Shalmon, B.; Tsoar, A.; et al. A standardized protocol to monitor Acacia trees in the Arava. Negev. Dead Sea Arava Stud. 2017, 9, 1-14.

32. Shrestha, M.K.; Stock, W.D.; Ward, D.; Golan-Goldhirsh, A. Water status of isolated Negev desert populations of Acacia raddiana with different mortality levels. Plant. Ecol. 2003, 168, 297-307. [CrossRef]

33. Enzel, Y.; Amit, R.; Grodek, T.; Ayalon, A.; Lekach, J.; Porat, N.; Bierman, P.; Blum, J.D.; Erel, Y. Late Quaternary weathering, erosion, and deposition in Nahal Yael, Israel: An "impact of climatic change on an arid watershed"? Geol. Soc. Am. Bull. 2012, 124, 705-722. [CrossRef]

34. Schick, A.P.; Lekach, J. An evaluation of two ten-year sediment budgets, Nahal Yael, Israel. Phys. Geogr. 1993, 14, 225-238. [CrossRef]

35. Kyalangalilwa, B.; Boatwright, J.S.; Daru, B.H.; Maurin, O.; Van Der Bank, M. Phylogenetic position and revised classification of Acacia s.l. (Fabaceae: Mimosoideae) in Africa, including new combinations in Vachellia and Senegalia. Bot. J. Linn. Soc. 2013, 172, 500-523. [CrossRef]

36. Israel Meteorological Service Data Base, Eilat Station 1972-2017. Available online: https://ims.data.gov.il/he/ims-results (accessed on 5 April 2018).

37. Noy-Meir, I. Desert ecosystems: Environment and producers. Annu. Rev. Ecol. Syst. 1973, 4, 25-51. [CrossRef]

38. Ogen, G. Acacia Trees at Nahal Shlomo after 18 Years of Drought. In Final Thesis in Biology and Earth Science; Maale Shaharut School: Yotvata, Israel, 2012.

39. Stavi, I.; Shem-Tov, R.; Gourjon, E.; Ragolski, G.; Shlomi, Y.; Ginat, H. Effects of 'red unit' deposit on Acacia trees in the hyper-arid southern Israel. Catena 2016, 145, 316-320. [CrossRef] 
40. Stavi, I.; Gusarov, Y.; Shem-Tov, R.; Lekach, J. Pseudo soil in hyper-arid ephemeral stream channel beds: Geo-ecological implications of the fluvio-pedogenic unit (FPU). Catena 2019, 173, 505-510. [CrossRef]

41. Sher, A.A.; Wiegand, K.; Ward, D. Do Acacia and Tamarix trees compete for water in the Negev desert? J. Arid Environ. 2010, 74, 338-343. [CrossRef]

42. Winters, G.; Ryvkin, I.; Rudkov, T.; Moreno, Z.; Furman, A. Mapping underground layers in the super arid Gidron Wadi using electrical resistivity tomography (ERT). J. Arid Environ. 2015, 121, 79-83. [CrossRef] 